https://helda.helsinki.fi

\title{
Long-term antipsychotic use and its association with outcomes in schizophrenia - the Northern Finland Birth Cohort 1966
}

\section{Moilanen, J. M.}

2016-08-01

Moilanen , J M , Haapea , M , Jaaskelainen , E , Veijola , J M , Isohanni , M K, Koponen , H J \& Miettunen , J 2016, ' Long-term antipsychotic use and its association with outcomes in schizophrenia - the Northern Finland Birth Cohort 1966 ' , European Psychiatry , vol. 36 , pp. 7-14 . https://doi.org/10.1016/j.eurpsy.2016.03.002

http://hdl.handle.net/10138/224225

https://doi.org/10.1016/j.eurpsy.2016.03.002

publishedVersion

Downloaded from Helda, University of Helsinki institutional repository.

This is an electronic reprint of the original article.

This reprint may differ from the original in pagination and typographic detail.

Please cite the original version. 
Original article

\title{
Long-term antipsychotic use and its association with outcomes in schizophrenia - the Northern Finland Birth Cohort 1966
}

\author{
J.M. Moilanen a,b,c,*, M. Haapea ${ }^{\text {b,c,d,e }}$, E. Jääskeläinen ${ }^{\text {a,b,c,e }}$,J.M. Veijola ${ }^{\text {a,b,c }}$, M.K. Isohanni ${ }^{\text {b,e }}$, \\ H.J. Koponen ${ }^{\mathrm{f}}$, J. Miettunen ${ }^{\mathrm{a}, \mathrm{b}, \mathrm{c}, \mathrm{e}}$ \\ ${ }^{a}$ University of Oulu, Department of Psychiatry, Research Unit of Clinical Neuroscience, Oulu, Finland \\ b Oulu University Hospital, Department of Psychiatry, Oulu, Finland \\ c Oulu University Hospital, University of Oulu, Medical Research Center Oulu, Oulu, Finland \\ d Oulu University Hospital, Department of Diagnostic Radiology, Oulu, Finland \\ ${ }^{\mathrm{e}}$ University of Oulu, Center for Life Course Health Research, Oulu, Finland \\ ${ }^{\mathrm{f}}$ Helsinki University Hospital, University of Helsinki, Psychiatry, Helsinki, Finland
}

\section{A R T I C L E I N F O}

\section{Article history:}

Received 11 December 2015

Received in revised form 2 March 2016

Accepted 3 March 2016

Available online 13 June 2016

\section{Keywords:}

Antipsychotics

Schizophrenia

Long-term

Outcome

\begin{abstract}
A B S T R A C T
Background: Due to the paucity of previous studies, we wanted to elucidate the pharmacoepidemiology of antipsychotics in schizophrenia in a general population sample, and the association between long-term antipsychotic use and outcomes.

Methods: The sample included 53 schizophrenia subjects from the Northern Finland Birth Cohort 1966 with at least ten years of follow-up (mean 18.6 years since illness onset). Data on lifetime medication and outcomes (remission, Clinical Global Impression [CGI], Social and Occupational Functioning Assessment Scale [SOFAS]) were collected from medical records, interviews, and national registers.

Results: During the first two years 22 (42\%), between two to five years 17 (32\%), and between five to ten years $14(26 \%)$ subjects had used antipsychotics less than half of the time. Drug-free periods became rarer during the follow-up. The mean lifetime daily dose of antipsychotics was $319 \mathrm{mg}$ in chlorpromazine equivalents. A high lifetime average and cumulative dose and antipsychotic polypharmacy were associated with a poorer outcome in all measures, whereas having no drug-free periods was associated with a better SOFAS score and a low proportion of time on antipsychotics with a better CGI score.

Conclusions: In our population-based sample, the use of antipsychotics increased during the first five years of illness and was relatively stable after that. Our results suggest that both low dose and proportion of use, and having no drug-free periods, are associated with better outcomes, which concords with current treatment recommendations and algorithms. High long-term doses and polypharmacy may relate to poor outcomes.
\end{abstract}

() 2016 Elsevier Masson SAS. All rights reserved.

\section{Introduction}

The effectiveness of antipsychotics on positive symptoms and relapse prevention in schizophrenia has been shown [1,2], but harmful side effects are common [1,3]. Antipsychotics are often used as a long-term maintenance treatment, although the clinical guidelines, such as those on dosing, are not consistent [4].

\footnotetext{
* Corresponding author. University of Oulu, Department of Psychiatry, Research Unit of Clinical Neuroscience, P.O. Box 5000, 90014 Oulu, Finland. Tel.: +358 440690706; fax: +358 8336169 .

E-mail address: jani.m.moilanen@student.oulu.fi (J.M. Moilanen).
}

The effectiveness of antipsychotics in the long-term has been questioned [5], and long-term use has even been suggested to be an iatrogenic cause of chronicity of schizophrenia [6,7]. This was not supported by the systematic review by Sohler et al. [8], in which they concluded that the published data was inadequate to answer the question about long-term treatment with antipsychotic medication causing harm. In consideration of neuroprotection versus neurotoxicity, relapses may be harmful [9]. On the other hand, imaging studies have suggested that some of the volume alterations shown in schizophrenia may be associated with antipsychotic treatment [10].

In the multinational incident cohorts of the World Health Organization, an average of $25.5 \%$ of patients with schizophrenic 
psychosis had not used antipsychotic medication during the last two years of the 15-year follow-up [11]. Earlier studies show that continuous medication after acute treatment decreases the risk of relapse during first two years, compared to medication withdrawal or intermittent antipsychotic treatment [5,12-14]. Long-term effects of dose lowering or discontinuation of antipsychotics are not fully known, because there is a lack of studies with a follow-up longer than two years. Wunderink et al. [15] stated that early dose reduction or discontinuation of antipsychotics in remitted firstepisode psychosis shows superior long-term functioning after seven years compared with maintenance treatment. However, these patients were at higher relapse risk during the first two years. In the longitudinal study by Harrow et al. [16-18], non-medicated individuals with schizophrenia had favorable outcomes compared to medicated ones. These results suggest different effects of antipsychotic treatment and non-medication or discontinuation in the short term and long-term.

Antipsychotic polypharmacy (APP) is common in the treatment of schizophrenia [19,20]. Evidence of the effectiveness of APP is lacking, even though APP may be effective in certain circumstances compared to monotherapy [21-23]. APP is associated with greater prevalence of adverse effects and increased costs [24], but no association between APP and increased mortality was found [25].

In summary, more information on long-term antipsychotic treatment with its benefits and drawbacks, and on antipsychotic non-medication or discontinuation, is needed [8]. In earlier studies within the Northern Finland Birth Cohort 1966 (NFBC 1966), we found that non-medicated subjects had favorable clinical outcomes [26], that length of non-medication was associated with increased gray matter volume [27], and that use of antipsychotics was associated with higher symptom scores and a higher number of hospital days [28].

Here we will study the associations between long-term antipsychotic use and outcomes within NFBC 1966. Our naturalistic, population-based sample offers an opportunity to explore the long-term use of antipsychotic medication, which is not possible in randomized controlled trials [29].

\subsection{Aims}

Our aim was to describe how individuals with schizophrenia use antipsychotics in the long-term, with a minimum of 10 years of illness, and to study the association between different characteristics of long-term antipsychotic use and outcomes.

\section{Methods}

\subsection{The Northern Finland Birth Cohort 1966}

The NFBC 1966 is an unselected, general population birth cohort based on 12,058 children born in the provinces of Lapland and Oulu [30]. The study design is approved by the local Ethics Committee. This study is based on a follow-up of the NFBC 1966 on psychosis, performed in 2008-2011, at approximately 43 years of age [28].

\subsection{Case description}

The principal source of hospitalization data was the Care Register for Health Care (hereafter the Care Register) covering all hospitals and health centers nationwide. The following information was used: psychosis diagnosis by 2008 according to the Care Register; indications of psychosis in the register data (i.e. sick leave [data -1999 ] or disability pension due to psychosis [-2000], or a right to reimbursement for psychoactive medication [-2005]); or self-reported psychosis or current high-dose antipsychotic use (over $300 \mathrm{mg}$ chlorpromazine equivalents) at 31 years of age in the questionnaire.

\subsubsection{Sample}

Out of 258 invited persons, 175 had a schizophrenia spectrum disorder diagnosis. Out of 69 participants, 53 had detailed information on long-term antipsychotic medication and a requested follow-up time lasting at least 10 years following the onset of illness. The formation of the study sample is shown in Fig. 1. Written informed consent and permission to collect medical data were obtained after they had been given a complete description of the study.

A Structured Clinical interview for DSM Axis I Disorders (SCID-I) interview leading to Diagnostic and Statistical Manual of Mental Disorders, 4th Edition (DSM-IV) lifetime diagnoses was performed at the follow-up. The participants' diagnoses were schizophrenia $(n=47)$, delusional disorder $(n=2)$, and schizoaffective disorder $(n=4)$. The diagnoses of non-participants and excluded subjects are given in Fig. 1.

The participants did not differ from the non-participants $(n=106)$ and those excluded due to missing data on medication $(n=8)$ or short follow-up time $(n=8)$ in terms of gender or diagnosis. The participants had illness onset at a younger age than the non-participants ( 23.9 vs. 28.3 years, $P<0.001$ ), and they had more hospital treatment days due to psychiatric disorders (545 vs. $360, P=0.045$ [for logarithmic transformations]). When adjusted for the onset age, the difference in treatment days did not remain significant.

\subsection{Data on medication}

Data on lifetime antipsychotic medication use were collected during 2008-2012 using all available hospital and outpatient records. The data were completed using the interviews conducted during the follow-up and the register of the Social Insurance Institution of Finland on psychoactive medications consumed during 1997. The medical records were obtained based on information from subjects' treatment facilities, which we received from the Care Register. If the subject had no information in the Care Register, medical records were requested from outpatient facilities. All medical records were reviewed to record the antipsychotic agent, dosage, and the time period the medication was used. The notifications in the medical records concerning the use of medication, such as whether a subject had hidden drugs or reported not using them, were taken into account while gathering data on medications. See the Supplementary Table for an exact description of the antipsychotics and chlorpromazine equivalents used. The data on antipsychotic medication has been used in earlier studies with shorter periods of follow-up [27,31,32].

\subsection{Variables}

\subsubsection{Background variables}

\subsubsection{Sex. Males versus females.}

2.4.1.2. Level of education. Low $=9$ years of non-vocational with a lower level of vocational education; middle $=9$ years of nonvocational with a higher level of vocational education, or 12 years of non-vocational with a lower level of vocational education; and high $=12$ years of non-vocational with a higher level of vocational education. Information from the follow-up questionnaire.

2.4.1.3. Marital status. Married or cohabiting versus others at the time of follow-up assessment. Information from the follow-up questionnaire. 


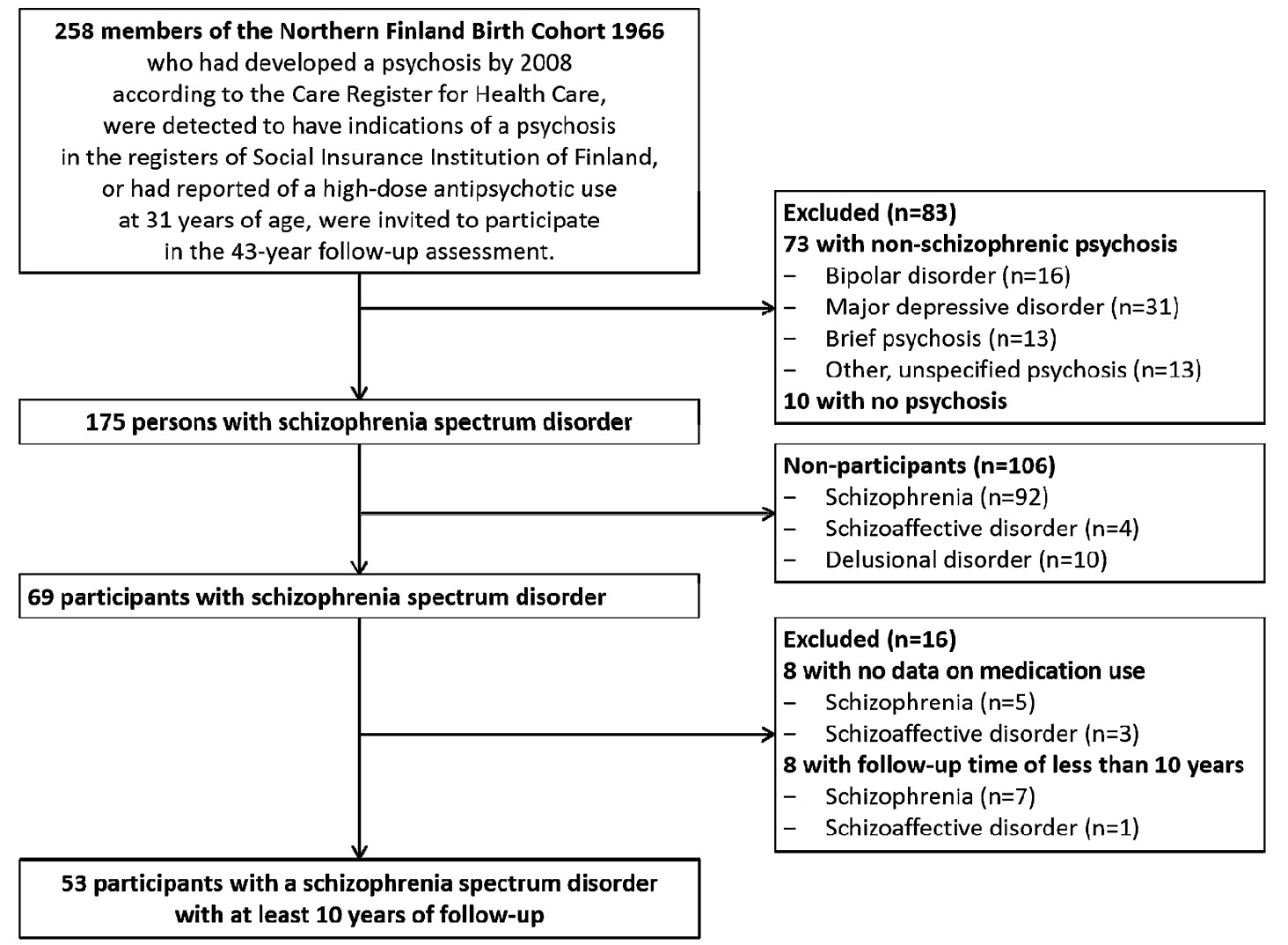

Fig. 1. The formation of the study sample and the ICD-10 diagnoses of the non-participants.

2.4.1.4. Parental psychosis. Parents' psychosis diagnosis in 19722012. Information from the Care Register.

2.4.1.5. Onset age. Ascertained from the medical records and health registers, and defined as the age when the first psychotic symptoms appeared [33].

2.4.1.6. Duration of follow-up. Duration of follow-up from the beginning of the treatment to the follow-up assessment varied from 10.3 to 26.7 years (mean 18.6 , SD 4.8 years).

2.4.1.7. Psychiatric hospitalization. Cumulative number of hospital treatment days and episodes due to any psychiatric disorder until the follow-up. Evaluated using the Care Register.

2.4.1.8. Psychiatric comorbidities. Substance use disorder or any other non-psychotic disorder (depressive, bipolar, anxiety, eating, or other disorder) until the end of follow-up. Information from the registers specified in the case description.

2.4.1.9. Somatic comorbidities. Somatic comorbidities included pulmonary diseases, cardiovascular diseases, endocrinological diseases, and others. Information from the follow-up questionnaire.

\subsubsection{Medication variables}

2.4.2.1. Long-term cumulative antipsychotic use. Long-term cumulative antipsychotic use during the follow-up, expressed as doseyears of a daily dose of $100 \mathrm{mg}$ chlorpromazine [27,34], was calculated as chlorpromazine equivalent $(\mathrm{mg})$ multiplied by the time on dose (years).

2.4.2.2. Proportion of time with medication since onset of treatmen$t$. Using the information on the days when subjects were on antipsychotic treatment, they were divided into three groups based on the regularity of daily antipsychotic use $(<50 \%, 50-95 \%$, $>95 \%$ of the time). The cut-offs were selected based on the distribution of the data. In order to study the proportion of antipsychotic use in different phases of illness, we did the abovementioned division for the first two years, two to five years, and five to ten years after the onset of illness, and for the whole followup time. Additionally, the proportions of time using typical or atypical antipsychotics, or both, for the whole follow-up were calculated.

2.4.2.3. Average dose when medicated. The average daily dose in chlorpromazine equivalents when using antipsychotics was classified as low ( $<300 \mathrm{mg}$ ) or high ( $\geq 300 \mathrm{mg}$ ).

2.4.2.4. Drug-free periods. Drug-free periods lasting for at least 30 days during the follow-up time (yes or no).

2.4.2.5. Antipsychotic polypharmacy (APP). Subjects were divided into three groups based on the proportion of time on APP, when using antipsychotic medication $(<5 \%, 5-40 \%,>40 \%)$. The cut-offs were selected based on the distribution of the data.

\subsubsection{Outcome variables}

2.4.3.1. Functioning. The Social and Occupational Functioning Assessment Scale (SOFAS) [35] uses a scale of 0-100, with higher scores reflecting better functioning. Subjects were divided into two groups: 0-60 points meaning impairments, and over 60 points meaning relatively good functioning.

2.4.3.2. Symptomatology and remission. Symptoms during the preceding week were measured during the interview using the Positive and Negative Syndrome Scale (PANSS) [36], which measures the number and extent of psychopathological 
symptoms, especially psychotic ones. Subjects were divided into remission groups based on the criteria of Andreasen et al. [37], with the exception that, as the symptoms had been assessed only once, the duration of remission criterion of six months was not applied. The symptom criteria for remission are: maximum scores of 3 in PANSS items P1, P2, P3, N1, N4, N6, G5, and G9.

2.4.3.3. Clinical outcome. Clinical Global Impression (CGI) [38] describes the severity of illness on a scale from 1 to 7 , where $1=$ healthy and $7=$ very ill. In the follow-up interview, subjects were divided into two groups: 4-7 points meaning at least moderately ill (poor clinical outcome), and 1-3 points meaning at most mildly ill (good clinical outcome).

\subsection{Statistical analyses}

The participants were compared with the non-participants using a $\mathrm{Chi}^{2}$ test, an independent samples $t$-test, or the analysis of variance. The illness-related background variables were compared between medication groups using a $\mathrm{Chi}^{2}$ test, a Kruskal-Wallis $\mathrm{H}$ test, or the one-way analysis of variance. A Chi ${ }^{2}$ test or MannWhitney's $U$ test was used to study the effect of medication variables on outcome variables. A Benjamini-Hochberg procedure was used to correct for multiple comparisons. If the association remained significant, a logistic regression analysis was used to control for selected confounding factors, such as for psychiatric hospital days and length of follow-up, which were used as proxy variables for the severity of illness. Long-term dose-years were used to control for total antipsychotic exposure. The logarithmic transformations of the hospital treatment days and the dose-years were used. $P$-values of less than 0.05 were considered statistically significant. IBM SPSS Statistics 22.0 was used.

\section{Results}

\subsection{Descriptive results of medication use}

At the follow-up interview, 43 (81\%) subjects used antipsychotics. During the first two years (from the illness onset), $22(42 \%)$ subjects had used antipsychotics less than $50 \%$ of the time, between two to five years $17(32 \%)$, between five to ten years 14 (26\%), and during the whole follow-up 13 (25\%). Males had used antipsychotics on average 69\% (median $86 \%$ ) and females $77 \%$ (median 88\%) of the follow-up time. The mean proportions of time with exposure to antipsychotics during the whole follow-up were $55.5 \%$ (SD 35.9) for typical and 35.2\% (SD 35.6) for atypical antipsychotics, and 9.9\% (SD 19.0) for both. Forty-four (83\%) subjects had drug-free periods lasting at least 30 days; 35 (66\%) during the first two years of the follow-up, 33 (62\%) between two to five years, and 23 (43\%) after five years.

Long-term cumulative antipsychotic use in the whole follow-up varied from 0 to 252 (mean 53, median 32) in dose-years. Only one subject was without antipsychotic treatment during the whole follow-up. The mean dose when using antipsychotics within the whole sample was $319 \mathrm{mg}$ in chlorpromazine equivalents (males, mean $350 \mathrm{mg}$, median $290 \mathrm{mg}$, range 0-1060 mg; females, $281 \mathrm{mg}$, median $246 \mathrm{mg}$, range $49-847 \mathrm{mg}$ ). The proportion of antipsychotic use and the mean doses when using medication during the ten-year follow-up after onset of illness are shown in Fig. 2. Mean dose increased from approximately 150 to 250 chlorpromazine equivalents. The proportion of those using antipsychotics was lowest after six months (53\%) and was relatively stable after five years (70\%).

\subsubsection{Background factors by the proportion of medication use}

Those who used antipsychotics less than $50 \%$ of the time were more often males, had a higher level of education, were more often married or in cohabitation, had become ill at an older age, and had better scores in PANSS at the follow-up assessment (Table 1). They had the smallest number of treatment episodes and treatment days, whereas those who used antipsychotics between 50 and 95\% of the time had the most.

\subsubsection{Psychiatric and somatic comorbidities}

Altogether, 12 subjects had been diagnosed with depression, 4 with bipolar disorder, 7 with anxiety disorder, 9 with harmful alcohol use or dependence, 9 with any substance use, and 1 with eating disorder. Altogether, 10 subjects reported having somatic comorbidities: pulmonary diseases $(n=3)$, cardiovascular diseases $(n=2)$, endocrinological diseases $(n=3)$, myasthenia gravis $(n=1)$, and Crohn's disease $(n=1)$.

\subsection{Association between medication use and outcome}

\subsubsection{Proportion of medication use}

Those who used antipsychotics less than $50 \%$ of the time had a better clinical outcome $(P=0.022)$ at the follow-up compared to those who used antipsychotics more than $50 \%$ of the time (Table 2 ).

\subsubsection{Average dose when medicated}

Subjects who had used less than $300 \mathrm{mg}$ of antipsychotic medication daily had a better outcome in all measures (SOFAS, $P=0.013$; remission, $P=0.026$; and CGI, $P=0.050$ ) compared to those who had used $300 \mathrm{mg}$ or more (Table 2). In SOFAS, the statistical significance remained after a Benjamini-Hochberg correction $(P=0.039)$ and when adjusted for the treatment days and the length of the follow-up $(P=0.041$ and $P=0.038$,
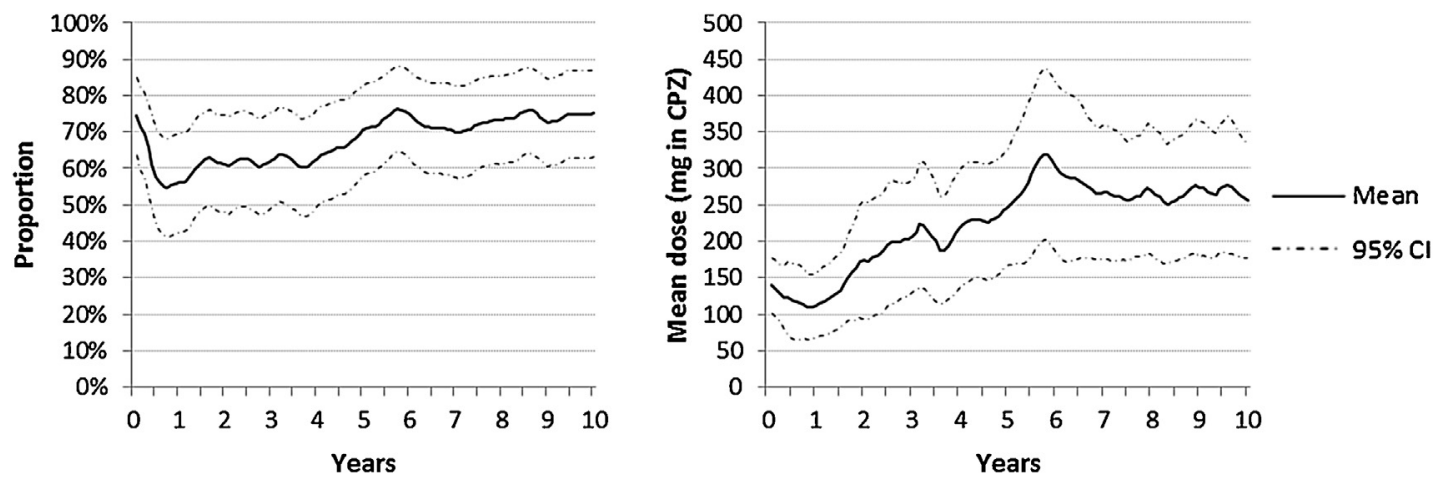

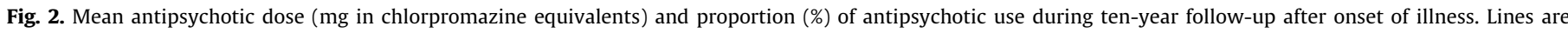
smoothed using 5-month moving averages. 
Table 1

Background factors by the proportion of antipsychotic medication use in the long-term.

\begin{tabular}{|c|c|c|c|c|c|}
\hline & \multicolumn{5}{|c|}{ Proportion of long-term antipsychotic use } \\
\hline & Total & $<50 \%(n=13)$ & $50-95 \%(n=22)$ & $>95 \%(n=18)$ & $P$-value \\
\hline $\operatorname{Sex}, n(\%)$ & & & & & $0.53^{\mathrm{a}}$ \\
\hline Male & $30(57 \%)$ & $9(69 \%)$ & $11(50 \%)$ & $10(56 \%)$ & \\
\hline Female & $23(43 \%)$ & $4(31 \%)$ & $11(50 \%)$ & $8(44 \%)$ & \\
\hline Education, $n(\%)$ & & & & & $0.47^{\mathrm{a}}$ \\
\hline Low & $30(58 \%)$ & $6(46 \%)$ & $13(59 \%)$ & $11(64 \%)$ & \\
\hline Middle & $11(21 \%)$ & $2(15 \%)$ & $6(27 \%)$ & $3(18 \%)$ & \\
\hline High & $11(21 \%)$ & $5(39 \%)$ & $3(14 \%)$ & $3(18 \%)$ & \\
\hline Marital status, $n(\%)$ & & & & & $0.37^{\mathrm{a}}$ \\
\hline Married or in cohabitation & $17(32 \%)$ & $6(46 \%)$ & $5(23 \%)$ & $6(33 \%)$ & \\
\hline Unmarried, divorced or widowed & $36(68 \%)$ & $7(54 \%)$ & $17(77 \%)$ & $12(67 \%)$ & \\
\hline Parental psychosis, $n(\%)$ & & & & & $0.27^{\mathrm{a}}$ \\
\hline Yes & $8(15 \%)$ & $3(23 \%)$ & $1(4.5 \%)$ & $4(22 \%)$ & \\
\hline No & $45(85 \%)$ & $10(77 \%)$ & $21(95.5 \%)$ & $14(78 \%)$ & \\
\hline Diagnosis, $n(\%)$ & & & & & $0.64^{\mathrm{a}}$ \\
\hline Schizophrenia & $47(89 \%)$ & $11(85 \%)$ & $19(86 \%)$ & $17(94 \%)$ & \\
\hline Other schizophrenia spectrum disorder & $6(11 \%)$ & $2(15 \%)$ & $3(14 \%)$ & $1(6 \%)$ & \\
\hline Onset age, mean $(S D)$ & $24.0(4.9)$ & $26.2(3.5)$ & $24.1(5.1)$ & $22.3(5.1)$ & $0.090^{\mathrm{b}}$ \\
\hline Duration of follow-up, mean (SD) & $18.6(4.8)$ & $16.0(3.8)$ & $18.3(4.8)$ & $20.8(4.5)$ & $0.019^{\mathrm{b}}$ \\
\hline \multicolumn{6}{|l|}{ Psychiatric treatment, median (IQR) } \\
\hline Episodes & $7(3-13.5)$ & $3(1.5-12)$ & $11(6-19)$ & $5.5(3-12)$ & $0.035^{\mathrm{c}}$ \\
\hline Days & $219(90-715)$ & $82(28-258)$ & $372(184-926)$ & $235(91-989)$ & $0.016^{\mathrm{c}}$ \\
\hline Long-term dose-years, median (IQR) & $32.2(14-77)$ & $3.3(1-11)$ & $33.1(19-74)$ & $74.3(4-118)$ & $<0.001^{\mathrm{c}}$ \\
\hline PANSS, total score, mean (SD) & $69.6(25.4)$ & $55.5(17.0)$ & $71.7(23.1)$ & $78.0(30.2)^{\mathrm{d}}$ & $0.048^{\mathrm{b}}$ \\
\hline
\end{tabular}

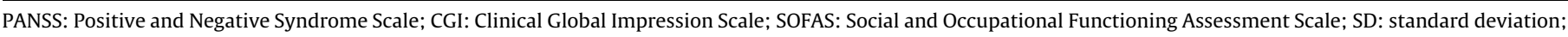
IQR: interquartile range.

a Significance from $\mathrm{Chi}^{2}$ test.

b Significance from One-way ANOVA.

c Significance from Kruskal-Wallis $\mathrm{H}$ test.

d $n=16$.

respectively), but not when adjusted for the total dose-years $(P=0.20)$. The proportion of antipsychotic use and the average dose when medicated during the first ten years of the follow-up, by functioning, remission, and clinical outcome, are shown in Fig. 3. The average dose was stable among those with good outcomes. The average dose increased during the follow-up among those with poor outcomes.

\subsubsection{Drug-free periods, polypharmacy, and cumulative use}

Having no drug-free periods (lasting at least 30 days) was associated with better functioning $(P=0.048)$ (Table 2). APP and long-term cumulative antipsychotic use were associated with poorer outcomes in all measures (Table 2), including when adjusted for the treatment days and the length of the follow-up. When adjusted for the total dose-years, APP remained

Table 2

The long-term use of antipsychotic medication and its association with outcome at the age of 43 years.

\begin{tabular}{|c|c|c|c|c|c|c|c|c|c|}
\hline & \multicolumn{2}{|c|}{ Functioning (SOFAS) } & \multirow[t]{3}{*}{$P$-value } & \multicolumn{2}{|l|}{ Remission $^{\mathrm{a}}$} & \multirow[t]{3}{*}{$P$-value } & \multicolumn{2}{|c|}{ Clinical outcome (CGI) } & \multirow[t]{3}{*}{$P$-value } \\
\hline & $\begin{array}{l}\text { Impairments } \\
(n=38)\end{array}$ & $\begin{array}{l}\text { Relatively good } \\
(n=15)\end{array}$ & & $\begin{array}{l}\text { No } \\
(n=35)\end{array}$ & $\begin{array}{l}\text { Yes } \\
(n=15)\end{array}$ & & $\begin{array}{l}\text { Poor } \\
(n=40)\end{array}$ & $\begin{array}{l}\text { Good } \\
(n=13)\end{array}$ & \\
\hline & $n(\%)$ & $n(\%)$ & & $n(\%)$ & $n(\%)$ & & $n(\%)$ & $n(\%)$ & \\
\hline Proportion of long-term antipsychotic use, $n$ (\%) & & & $0.23^{\mathrm{b}}$ & & & $0.096^{\mathrm{b}}$ & & & $0.022^{\mathrm{b}}$ \\
\hline$<50 \%$ & $7(54 \%)$ & $6(46 \%)$ & & $6(46 \%)$ & $7(54 \%)$ & & $6(46 \%)$ & $7(54 \%)$ & \\
\hline $50-95 \%$ & $18(82 \%)$ & $4(18 \%)$ & & $18(82 \%)$ & $4(18 \%)$ & & $19(86 \%)$ & $3(14 \%)$ & \\
\hline$>95 \%$ & $13(72 \%)$ & $5(28 \%)$ & & $11(73 \%)$ & $4(27 \%)$ & & $15(83 \%)$ & $3(17 \%)$ & \\
\hline Average dose, ${ }^{\mathrm{C}} n(\%)$ & & & $0.013^{\mathrm{b}, \mathrm{g}}$ & & & $0.026^{\mathrm{b}}$ & & & $0.050^{\mathrm{b}}$ \\
\hline$<300 \mathrm{CPZ}$ & $18(58 \%)$ & $13(42 \%)$ & & $18(58 \%)$ & $13(42 \%)$ & & $20(65 \%)$ & $11(35 \%)$ & \\
\hline$\geq 300 \mathrm{CPZ}$ & $20(91 \%)$ & $2(9 \%)$ & & $17(81 \%)$ & $2(11 \%)$ & & $20(91 \%)$ & $2(9 \%)$ & \\
\hline Drug-free periods, ${ }^{\mathrm{d}} n(\%)$ & & & $0.048^{\mathrm{b}}$ & & & $0.20^{\mathrm{b}}$ & & & $0.66^{\mathrm{b}}$ \\
\hline No & $4(44 \%)$ & $5(56 \%)$ & & $4(50 \%)$ & $4(50 \%)$ & & $6(67 \%)$ & $3(33 \%)$ & \\
\hline Yes & $34(79 \%)$ & $9(21 \%)$ & & $31(76 \%)$ & $10(24 \%)$ & & $34(79 \%)$ & $9(21 \%)$ & \\
\hline Antipsychotic polypharmacy, ${ }^{\mathrm{e}} n(\%)$ & & & $0.002^{\mathrm{b}, \mathrm{g}}$ & & & $0.003^{b, g}$ & & & $0.002^{\mathrm{b}, \mathrm{s}}$ \\
\hline$<5 \%$ & $11(48 \%)$ & $12(52 \%)$ & & $11(48 \%)$ & $12(52 \%)$ & & $12(52 \%)$ & $11(48 \%)$ & \\
\hline $5-40 \%$ & $13(81 \%)$ & $3(19 \%)$ & & $12(80 \%)$ & $3(20 \%)$ & & $14(87 \%)$ & $2(13 \%)$ & \\
\hline$>40 \%$ & $14(100 \%)$ & $0(0 \%)$ & & $12(100 \%)$ & $0(0 \%)$ & & $14(100 \%)$ & $0(0 \%)$ & \\
\hline Long-term dose-years, median (IQR) & $41(19-96)$ & $19(2-27)$ & $0.004^{f, g}$ & $36(19-85)$ & $11(1-30)$ & $0.003^{f, g}$ & $41(21-92)$ & $9(1-23)$ & $0.001^{\mathrm{f}, \mathrm{g}}$ \\
\hline
\end{tabular}

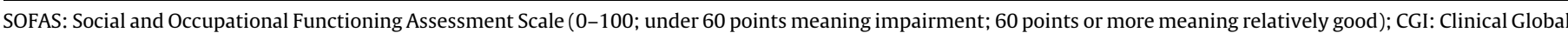
Impression scale (1-7; 4-7 meaning clinically poor; 1-3 meaning clinically good).

a Remission criteria: maximum scores of 3 in PANSS items P1, P2, P3, N1, N4, N6, G5, and G9.

b Significance from $\mathrm{Chi}^{2}$ test.

c Average daily dose in chlorpromazine equivalents (CPZ) when using antipsychotic medication.

d Any drug-free period lasting at least 30 days.

e Proportion of antipsychotic polypharmacy when using antipsychotic medication.

f Significance from Mann-Whitney's $U$ test.

g Significant after Benjamini-Hochberg correction. 


\section{Functioning (SOFAS)}

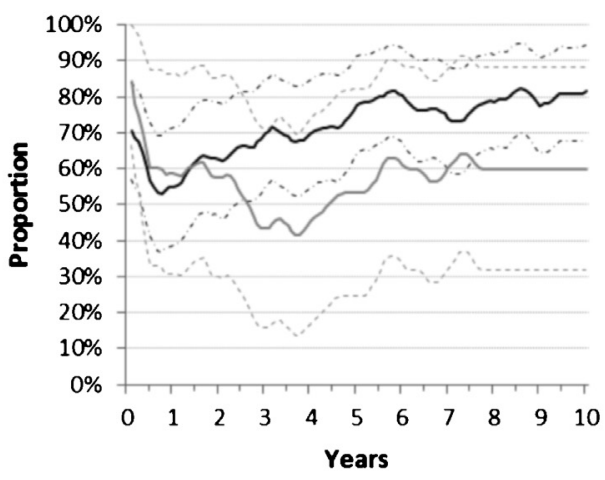

\section{Remission}

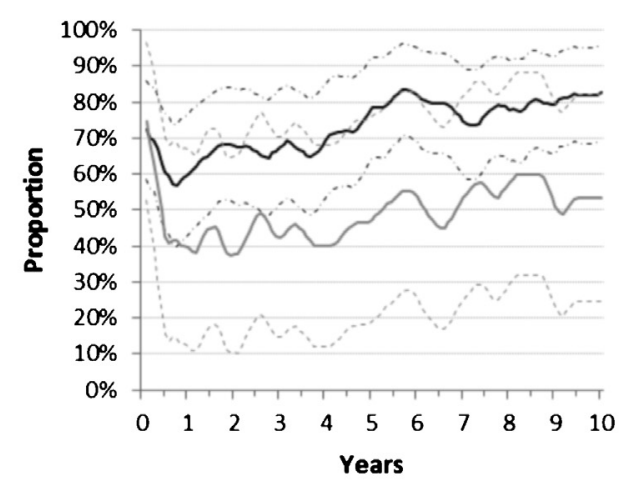

\section{Clinical Global Impression (CGI)}

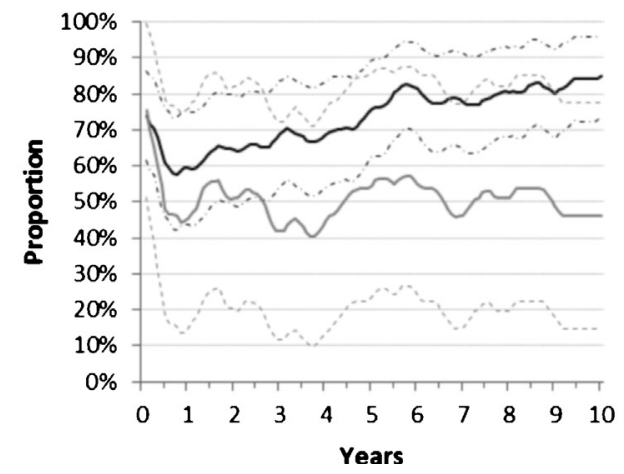

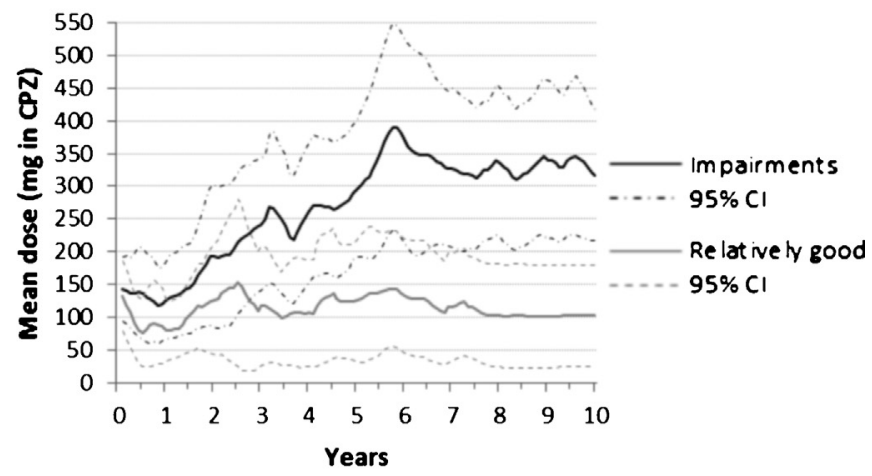
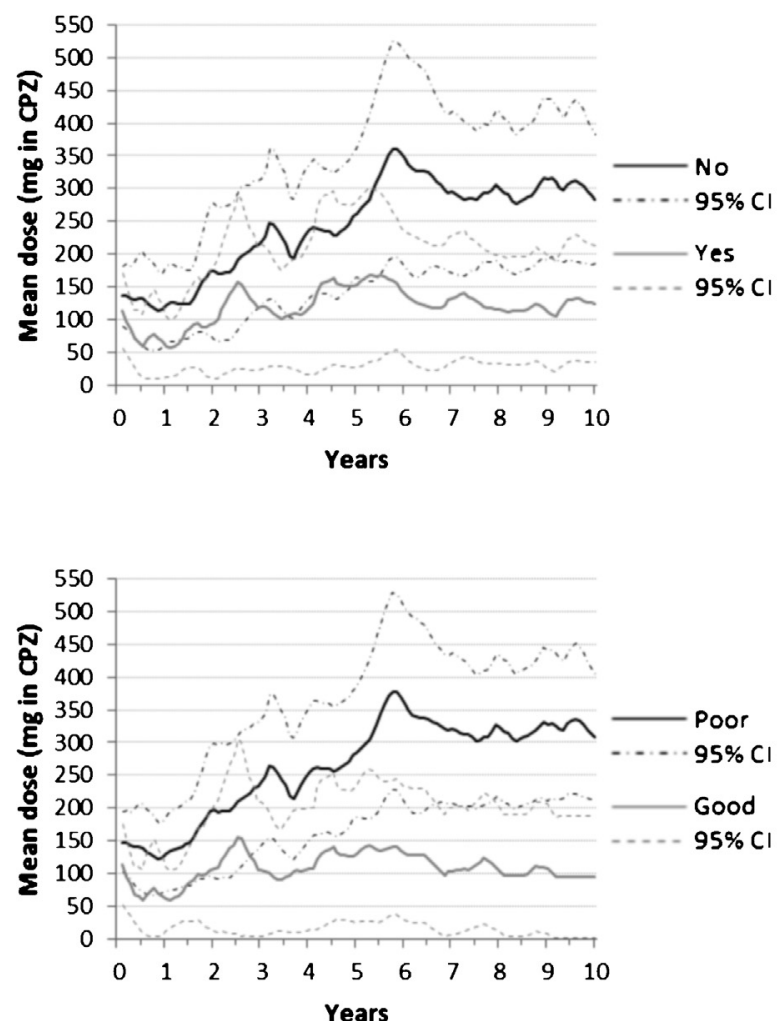

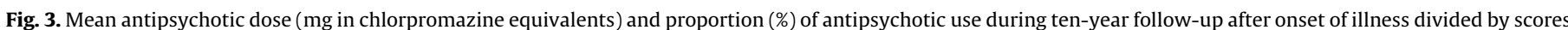

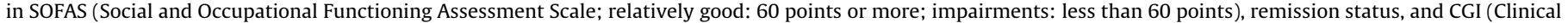
Global Impression scale; good: from 1 to 3; poor: from 4 to 7). Lines are smoothed using 5-month moving averages.

significantly associated with SOFAS and CGI, but not with remission $(P=0.068)$.

\section{Discussion}

\subsection{Main results}

In total, $42 \%$ of the subjects had used antipsychotics less than $50 \%$ of the time during the first two years of the follow-up, $32 \%$ between two to five years, $26 \%$ between five to ten years, and $25 \%$ during the whole follow-up. Drug-free periods became rarer during the follow-up, indicating steadier antipsychotic use over time.

In the analyses of medication use and outcome, a low antipsychotic dose was associated with a better outcome in all measures, a low proportion of time on antipsychotics with better
CGI, and no drug-free periods with better SOFAS. APP and higher long-term cumulative antipsychotic use were associated with a poorer outcome in all measures.

\subsection{Long-term antipsychotic use}

We described the proportion of antipsychotic use for ten years after the onset of illness. This is close to the term compliance (the notifications in the medical records concerning untaken described antipsychotics were taken into account), which has been defined as "the extent to which a person's behavior coincides with the medical advice he/she has received" [39]. Because compliance is not an all-or-nothing phenomenon, the term partial compliance is used [40]. In the review by Llorca [40], rates of partial compliance with antipsychotics increased over time with discharge from an inpatient facility, 50\% within one year, and 75\% within two years. 
Our follow-up was longer, with the proportion of antipsychotic use becoming higher after the first years, and remaining at a higher level after five years of illness, which has not been shown in earlier studies.

\subsection{Long-term antipsychotic use and outcomes}

Systematic information on long-term use of antipsychotic medication is rare. Harrow et al. [17,41] concluded, in their 20-year follow-up study, that not all schizophrenia subjects need continuous antipsychotic medication for a prolonged period. There are also contrary findings questioning the discontinuation of antipsychotic medication [14] and intermittent treatment [13]. These findings concern the early stage of illness, except for the review by Gilbert et al. [12], which studied the withdrawal of antipsychotics mainly within multi-episode schizophrenia. Our results concerning better social and occupational functioning with steady medication supports the preference for continuous antipsychotic treatment over intermittent. On the other hand, we found a better CGI score among subjects who had used antipsychotics less than half of the time, which suggests interindividual variations in drug response.

Treatment guidelines, such as the guidelines of the American Psychiatric Association [42], recommend maintenance treatment. However, the lowest dose needed is recommended, and after a symptom-free period (the duration varies between guidelines) the gradual discontinuation of antipsychotics is possible. Our results support these recommendations. Within our sample, a good outcome was observed among those who had a low dose, had no drug-free periods, and used medication less than half of the time. Concerning the latter, it is, however, impossible to say whether those subjects with a good outcome and antipsychotic use less than half of the time fulfill the criteria of guided discontinuation as laid down in the guidelines.

APP could be used in some clinically difficult conditions [22]. This could also explain our results concerning the association between APP and poorer outcomes. More severe illness could also explain the association between higher long-term cumulative antipsychotic use and poorer outcome, as increasing the dose of antipsychotics is one strategy in treating treatment-resistance [43]. This could also be considered from the pharmacogenetic viewpoint, while many subjects do not respond well to antipsychotic treatment $[44,45]$.

\subsection{Strengths and limitations}

Having a population-based sample offers an opportunity to study naturalistic long-term antipsychotic medication use in schizophrenia. Studies of long-term antipsychotic use in natural settings are rare.

Detailed medication data are a considerable strength. All the available medical records were reviewed, and the data were completed with interviews and register data.

Our epidemiologically sound, population-based sample, consisting mostly of outpatients and some people without psychiatric treatment, may reflect less severe illness than in many clinical settings. To decrease the risk of residual confounding in our naturalistic setting with a long follow-up, the most important confounders related to the duration and severity of illness were taken into account. However, subjects with more severe illness or treatment-resistant schizophrenia may receive higher doses of antipsychotic medication, making higher doses a marker of a more serious illness rather than a cause of decline. Nonetheless, it cannot be ruled out, especially with the cumulative evidence from other studies of potentially harmful effects of years of antipsychotic use on cognition [31], brain structures, and functioning [32], that the findings reflect a true causal association.

The limitations are that the sample was small and the subjects were in different phases of the illness. We had one follow-up assessment of outcomes, which makes it difficult to interpret associations between medication and outcome as causal. Limitations of the data on medication are: a lack of information on the use of other medication, such as anxiolytics or mood stabilizers; the register data were only available for the year 1997; and we had no information on symptoms or exposure to antipsychotics among non-participants making non-response bias possible.

\subsection{Conclusions}

Schizophrenia is a heterogeneous condition, and so are responses to antipsychotics. Clinically, it is important to detect these different drug response groups, including those managing with low doses or tolerating pauses or even discontinuation.

In our sample, the use of antipsychotic medication increased during, and was relatively stable after, the first five years of illness. A higher long-term cumulative dose and antipsychotic polypharmacy were associated with a poorer outcome in all measures, reflecting perhaps treatment resistance. A better outcome in all measures was associated with a low dose, better CGI with a proportion of use less than half of the time, and better SOFAS with having no drug-free periods. These findings regarding a better outcome point to heterogeneity of schizophrenia, and also raise questions for future research on how to identify subjects with schizophrenia who benefit from long-term medication, and subjects who manage without doses or with low doses.

\section{Disclosure of interest}

The authors declare that they have no competing interest.

\section{Funding/Support}

This work was supported by unrestricted grants from the Academy of Finland (grants 132071, 268336, and 278286), the Northern Finland Health Care Support Foundation, the Jalmari and Rauha Ahokas Foundation, the Oy H. Lundbeck Foundation, the Sigrid Jusélius Foundation, and the NARSAD: Brain and Behavior Research Fund.

\section{Appendix A. Supplementary data}

Supplementary data associated with this article can be found, in the online version, at http://dx.doi.org/10.1016/j.eurpsy.2016.03. 002.

\section{References}

[1] Tandon R, Belmaker RH, Gattaz WF, Lopez-Ibor Jr JJ, Okasha A, Sinqh B, et al. World Psychiatric Association pharmacopsychiatry section statement on comparative effectiveness of antipsychotics in the treatment of schizophrenia. Schizophr Res 2008;100(1-3):20-38.

[2] Bruijnzeel D, Suryadevara U, Tandon R. Antipsychotic treatment of schizophrenia: an update. Asian J Psychiatr 2014;11:3-7.

[3] Young SL, Taylor M, Lawrie SM. "First do no harm." A systematic review of the prevalence and management of antipsychotic adverse effects. J Psychophrmacol 2015;29(4):353-62.

[4] Takeuchi H, Suzuki T, Uchida H, Watanabupe K, Mimura M. Antipsychotic treatment for schizophrenia in the maintenance phase: a systematic review of the guidelines and algorithms. Schizophr Res 2012;134(2-3):219-25.

[5] Leucht S, Tardy M, Komossa K, Heres S, Kissling W, Salanti G, et al. Antipsychotic drugs versus placebo for relapse prevention in schizophrenia: a systematic review and meta-analysis. Lancet 2012;379(9813):2063-71.

[6] Whitaker R. Anatomy of an epidemic: magic bullets, psychiatric drugs, and the astonishing rise of mental illness in America. New York: Broadway Paperbacks; 2010. 
[7] Whitaker R. The case against antipsychotic drugs: a 50-year record doing more harm than good. Med Hypotheses 2014;62(1):5-13.

[8] Sohler N, Adams BG, Barnes DM, Cohen GH, Prins SJ, Schwartz S. Weighing the evidence for harm from long-term treatment with antipsychotic medications: a systematic review. Am J Orthopsychiat 2015 [Epub ahead of print]http://dx. doi.org/10.1037/ort0000106.

[9] Emsley R, Chiliza B, Asmal L. The evidence for illness progression after relapse in schizophrenia. Schizophr Res 2013;148(1-3):117-21.

[10] Fusar-Poli P, Smieskova R, Kempton MJ, Ho BC, Andreasen NC, Borgwardt S. Progressive brain changes in schizophrenia related to antipsychotic treatment?. A meta-analysis of longitudinal MRI studies. Neurosci Biobehav Rev 2013;37(8):1680-91.

[11] Hopper K, Harrison G, Wanderling JA. An overview of course and outcome in ISoS. In: Hopper K, Harrison G, Janca A, Sartorius N, editors. Recovery from schizophrenia. An international perspective. Oxford University Press; 2007 [Table 3.6].

[12] Gilbert PL, Harris MJ, McAdams LA, Jeste DV. Neuroleptic withdrawal in schizophrenic patients. A review of the literature. Arch Gen Psychiatry 1995;52:173-88.

[13] Sampson S, Joshi K, Mansour M, Adams CE. Intermittent drug techniques for schizophrenia. Schizophr Bull 2013;39(5):960-1.

[14] Zipursky RB, Menezes NM, Streiner DR. Risk of symptom recurrence with medication discontinuation in first-episode psychosis: a systematic review. Schizophr Res 2014;152(2-3):408-14.

[15] Wunderink L, Nieboer RM, Wiersma D, Sytema S, Nienhuis FJ. Recovery in remitted first-episode psychosis at 7 years of follow-up of an early dose reduction/discontinuation or maintenance treatment strategy: long-term follow-up of a 2-year randomized clinical trial. JAMA Psychiatry 2013;70(9): 913-20.

[16] Harrow M, Jobe TH. Factors involved in outcome and recovery in schizophrenia patients not on antipsychotic medications: a 15-year multifollow-up study. J Nerv Ment Dis 2007;195:406-14.

[17] Harrow M, Jobe TH, Faull RN. Do all schizophrenia patients need antipsychotic treatment continuously throughout their lifetime?. A 20-year longitudinal study. Psychol Med 2012;42(10):2145-55.

[18] Harrow M, Jobe TH, Faull RN. Does treatment of schizophrenia with antipsychotic medication eliminate or reduce psychosis?. A 20-year multi-follow-up study. Psychol Med 2014;44:3007-16.

[19] Gallego JA, Bonetti J, Zhang J, Kane JM, Correl CU. Prevalence and correlates of antipsychotic polypharmacy: a systematic review and meta-regression of global and regional trends from the 1970s to 2009. Schizophr Res 2012;138(1):18-28.

[20] Suokas JT, Suvisaari JM, Haukka J, Korhonen P, Tiihonen J. Description of longterm polypharmacy among schizophrenia outpatients. Soc Psychiatry Psychiatr Epidemiol 2013;48:631-8.

[21] Correll CU, Rummel-Kluge C, Corves C, Kane JM, Leucht S. Antipsychotic combinations vs. monotherapy in schizophrenia: a meta-analysis of randomized controlled trials. Schizophren Bull 2009;35(2):443-57.

[22] Fleischacker WW, Uchida H. Critical review of antipsychotic polypharmacy in the treatment of schizophrenia. Int J Neuropsychopharmacol 2014;17(7): 1083-93.

[23] Iasevoli F, Buonaquro EF, Marconi M, Di Giovambattista E, Rapagnani MP, De Berardis D, et al. Efficacy and clinical determinants of antipsychotic polypharmacy in psychotic patients experiencing an acute relapse and admitted to hospital stay: results from a cross-sectional and a subsequent longitudinal pilot-study. ISRN Pharmacol 2014;2014:762127. http://dx.doi.org/10.1155/ 2014/762127.

[24] Lochmaan van Bennekom MW, Gijsman HJ, Zitman FG. Antipsychotic polypharmacy in psychotic disorders: a critical review of neurobiology, efficacy, tolerability and cost effectiveness. J Psychopharmacol 2013;27(4):327-36.

[25] Tiihonen J, Suokas JT, Suvisaari JM, Haukka J, Korhonen P. Polypharmacy with antipsychotics, antidepressants, or benzodiazepines and mortality in schizophrenia. Arch Gen Psychiatry 2012;69:476-83.
[26] Moilanen J, Haapea M, Miettunen J, Jääskeläinen E, Veijola J, Isohanni M, et al. Characteristics of subjects with schizophrenia spectrum disorder with and without antipsychotic medication - a 10-year follow-up of the Northern Finland 1966 Birth Cohort study. Eur Psychiatry 2013;28(1):53-8.

[27] Moilanen J, Huhtaniska S, Haapea M, Jääskeläinen E, Veijola J, Isohanni M, et al. Brain morphometry of individuals with schizophrenia with and without antipsychotic medication - the Northern Finland Birth Cohort 1966 study. Eur Psychiatry 2015;30(5):598-605.

[28] Nykänen S, Puska V, Tolonen J-P, Salo H, Isohanni M, Koponen $\mathrm{H}$, et al. Use of psychiatric medications in schizophrenia and other psychoses in a general population sample. Psychiatry Res 2015, http://dx.doi.org/10.1016/j.psychres 2015.11.013.

[29] Wang P, Brookhart A, Ulbricht C, Schneeweiss N. The pharmacoepidemiology of psychiatric medications. In: Ming T, Tsuang MT, Tohen M, Jones PB, editors. Textbook in psychiatric epidemiology. 3rd ed, John Wiley \& Sons, Ltd; 2011. p. 155-65.

[30] Jääskeläinen E, Haapea M, Rautio N, Juola J, Penttilä M, Nordström T, et al. Twenty years of schizophrenia research in the Northern Finland Birth Cohort 1966 - a systematic review. Schizophr Res Treatm 2015;2015:524875.

[31] Husa AP, Rannikko I, Moilanen J, Haapea M, Murray GK, Barnett J, et al. Lifetime use of antipsychotic medication and its relation to change of verbal learning and memory in midlife schizophrenia - an observational 9-year follow-up study. Schizophr Res 2014;158(1-3):134-41.

[32] Veijola J, Guo JY, Moilanen JS, Jääskeläinen E, Miettunen J, Kyllönen M, et al. Longitudinal changes in total brain volume in schizophrenia: relation to symptom severity, cognition and antipsychotic medication. PLoS One 2014;9:e101689.

[33] Penttilä M, Jääskeläinen E, Haapea M, Tanskanen P, Veijola J, Ridler K, et al. Association between duration of untreated psychosis and brain morphology in schizophrenia within the Northern Finland 1966 Birth Cohort. Schizophr Res 2010;123(2-3):145-52.

[34] Kroken RA, Johnsen E, Ruud T, Wentzel-Larsen T, Jørgensen HA. Treatment of schizophrenia with antipsychotics in Norwegian emergency wards, a crosssectional national study. BMC Psychiatry 2009;9:24.

[35] Spitzer RL, Gibbon M, Endicott J. Global Assessment Scale (GAS), Global Assessment of Functioning (GAF) scale, Social and Occupational Functional Assessment Scale (SOFAS). In: Rush JA, et al., editors. Handbook of Psychiatric Measures. Washington: American Psychiatric Association; 2000. p. 96-100.

[36] Kay SR, Fiszbein A, Opler LA. The positive and negative syndrome scale (PANSS) for schizophrenia. Schizophr Bull 1987;13:261-76.

[37] Andreasen NC, Carpenter WT, Kane JM, Lasser RA, Marder SR, Weinberger DR. Remission in schizophrenia: proposed criteria and rationale for consensus. Am J Psychiatry 2005;162:441-9.

[38] Guy W. EDCEU Assessment Manual for Psychopharmacology-Revised (DHEW Pupl No ADM 76 338). Rockville, MD, U.S: Department of Health, Education, and Welfare, Public Health Service, Alcohol, Drug Abuse, and Mental Health Administration, NIMH Psychopharmacology Research Branch, Division of Extramural Research Programs; 1976. p. 534-7.

[39] Kampman O, Lehtinen K. Compliance in psychoses. Acta Psychiatrica Scandinavica 1999;100:167-75.

[40] Llorca P-M. Partial compliance in schizophrenia and the impact on patient outcomes. Psychiatry Res 2008;161(2):235-47.

[41] Harrow M, Jobe TH. Does long-term treatment of schizophrenia with antipsychotic medications facilitate recovery. Schizophr Bull 2013;39(5):362-5.

[42] American Psychiatric Association. Practice guideline for the treatment of patients with schizophrenia. Washington, DC: APA; 2010.

[43] Dold M, Leucht S. Pharmacotherapy of treatment-resistant schizophrenia: a clinical perspective. Evid Based Ment Health 2014;17(2):33-7.

[44] Arranz MJ, Rivera M, Munro JC. Pharmacogenetics of response to antipsychotics in patients with schizophrenia. CNS Drugs 2011;25(11):933-69.

[45] Xu Q, Wu X, Xiong Y, Xing Q, He L, Qin S. Pharmacogenetics can improve antipsychotic treatment in schizophrenia. Front Med 2013;7(2):180-90. 